\title{
Highly Ordered Pd Nanowire Array by Template Fabrication for Propanol Electrooxidation
}

\author{
Zhihong Sun, ${ }^{1}$ Faliang Cheng, ${ }^{2}$ and Xiangcheng Dai ${ }^{3}$ \\ ${ }^{1}$ Department of Computer and Information Science, City College of Dongguan University of Technology, \\ Dongguan 523106, China \\ ${ }^{2}$ Faculty of Chemical Biotechnology, Dongguan University of Technology, Dongguan 523106, China \\ ${ }^{3}$ Department of Chemistry, Anhui University, Anhui Province 230039, China \\ Correspondence should be addressed to Faliang Cheng, chengfl@dgut.edu.cn
}

Received 16 April 2009; Revised 21 June 2009; Accepted 23 August 2009

Recommended by Peter Stockwell

\begin{abstract}
Highly ordered Pd nanowire arrays (NWAs) prepared by electrodeposition method using the fresh prepared anodic aluminum oxide (AAO) as the template have been characterized by X-ray diffraction pattern (XRD), X-ray photoelectron spectroscopy (XPS), transmission electron microscope (TEM), scanning electron microscopy (SEM), and electrochemical measurements. SEM results revealed that the brush-shaped Pd NWAs are dispersed uniformly. The diameter and length of the obtained Pd NWAs are about $50 \mathrm{~nm}$ and $850 \mathrm{~nm}$, respectively. Furthermore, the electrocatalytic activity of Pd NWAs electrode for propanol oxidation in alkaline media has also been studied. It is found that the obtained nanostructurs exhibit excellent electrocatalytic activity toward the oxidation of propanol, demonstrating the potential application in portable direct alcohol fuel cells (DAFCs).
\end{abstract}

Copyright (C) 2009 Zhihong Sun et al. This is an open access article distributed under the Creative Commons Attribution License, which permits unrestricted use, distribution, and reproduction in any medium, provided the original work is properly cited.

\section{Introduction}

DAFCs have been attracted considerable interests as powder sources in portable electronic devices because they have a variety of merits, including low operating temperatures, ease of handling liquid fuel, and the high-energy density [1-4]. In DAFCs, alcohol such as methanol, ethanol, and propanol is used as the fuel instead of hydrogen. Among them, propanol is less toxic, not easy to crossover to the cathode than methanol [5-7]. Precious metal Pt is commonly employed as the anode material for electrocatalytic oxidation of propanol in DAFCs [8-16]. However, the electrooxidation of propanol on $\mathrm{Pt}$ is complicated because of generation of strongly chemisorbed reaction intermediates such as $\mathrm{CO}, \mathrm{COH}$, and HCO [17]. Furthermore, the chemisorbed species often poison Pt or Pt-based catalyst during the electrooxidation reaction. To avoid this poisoning, some other metals such as Pd-based catalysts were considered as the substitution for the $\mathrm{Pt}$, which exhibited a positive effect on catalytic activity with respect to alcohol oxidation.
NWAs have received intense research interest due to their unique properties and potential applications, for example, nanoscale electronics, optoelectronics, and magnetics. Research results indicate that the uniform-ordered NWAs as electrode materials can enhance electrochemical performances owing to their large surface area. Among various techniques, the method using AAO template can easily control the parameters of NWAs [18-22]. Moreover, electrodeposition also has some notable advantage, which can precisely control of the position and composition of the nanowires along their lengths.

Here, AAO films were successfully grown on a Ti substrate and then used as templates to synthesize high surface area and ordered Pd NWAs for propanol electrooxidation.

\section{Experimental}

Porous AAO templates were fabricated through a twostep anodization process [23]. Prior to anodization, highpurity aluminum foils $(99.999 \%)$ were annealed at $500^{\circ} \mathrm{C}$ 
for 3 hours in vacuum, followed by degreasing in acetone. Anodization was carried out in $0.3 \mathrm{M} \mathrm{H}_{2} \mathrm{C}_{2} \mathrm{O}_{4}$ solution under a constant direct current voltage of $40 \mathrm{~V}$ at $10^{\circ} \mathrm{C}$ for 2 hours. The alumina layer formed during the anodization step was removed in a mixture of phosphoric acid (5 $\mathrm{wt} \%)$ and chromic acid ( $2 \mathrm{wt} \%)$ at $60^{\circ} \mathrm{C}$ for 30 minutes. Then the aluminum foil was oxidized again at the same conditions for 6 hours. Then AAO template was etched in a saturated $\mathrm{SnCl}_{4}$ to remove the remaining aluminum. The AAO template was treated again in a $10 \mathrm{wt} \%$ phosphoric acid solution at $25^{\circ} \mathrm{C}$ for 50 minutes to remove the barrier layer on the other side of the aluminum foil.

A Ti foil with the thickness of $0.1 \mathrm{~mm}$ was polished and thoroughly cleaned. A piece of as-prepared AAO template was attached to the polished surface of the Ti foil. Electrodeposition was carried out in an aqueous solution containing $2 \mathrm{~g} \mathrm{~L}^{-1} \mathrm{Pd}\left(\mathrm{NH}_{3}\right)_{4} \mathrm{Cl}_{2}+20 \mathrm{~g} \mathrm{~L}^{-1} \mathrm{NH}_{4} \mathrm{Cl}$. The $\mathrm{pH}$ value of the solution was adjusted to 8 with $\mathrm{NH}_{3} \cdot \mathrm{H}_{2} \mathrm{O}$. The Pd NWAs electrode was prepared using the potential of $-0.6 \mathrm{~V}$ for 40 minutes under stirring. All of the solutions were prepared by using distilled water and were purged with Ar before experiment. The Pd NWAs embedded in AAO were lastly dipped into $2 \mathrm{M} \mathrm{NaOH}$ solution for 1 hour to remove the AAO completely and washed by distilled water several times. The deposition of the Pd film electrode was carried out on the Ti foil under conditions similar to that for the Pd NWA electrode.

Electrochemical experiments were performed on a PARSTAT 2273 electrochemical workstation (Princeton, USA) at $30^{\circ} \mathrm{C}$ using a standard three-electrode cell. A platinum foil $\left(2.0 \mathrm{~cm}^{2}\right)$ and saturated calomel electrode (SCE) were used as the counter and reference electrodes, respectively. XRD was carried out on a D/MAX2200 diffractometer employing $\mathrm{Cu} \mathrm{Ka}$ radiation $(k=0.15418 \mathrm{~nm})$. The SEM analysis was performed using a Hitachi S-5200. High-resolution transmission electron microscopy (HRTEM) images and energy-dispersive X-ray (EDX) analysis were carried out with a JEOL-2010 TEM at an accelerating voltage of $200 \mathrm{kV}$. XPS was performed on ESCALAB MKII with Mg $\mathrm{K} \alpha(h \nu=1253.6 \mathrm{eV})$ as the excitation source. The binding energies obtained in the XPS spectral analysis were corrected for specimen charging by referencing the $\mathrm{C}_{1 \mathrm{~s}}$ to $284.8 \mathrm{eV}$.

\section{Results and Discussion}

The XRD pattern of the Pd NWAs electrode is shown in Figure 1. All peaks can be assigned to the Pd face-centeredcubic (fcc) lattice structure based on the data of the JCPDS file. The strong diffraction peaks at the Bragg angles of $40.1^{\circ}$, $46.5^{\circ}$, and $68.1^{\circ}, 82.1^{\circ}$, and $86.6^{\circ}$ are correspond to the (111), (200), and (220) facets of palladium crystal.

To further characterize the product, XPS is carried out to investigate the surface compositions and chemical states of the as-prepared product, and the results are shown in Figure 2. The binding energies obtained in the XPS analysis are corrected for specimen charging by referencing the $\mathrm{C}_{1 \mathrm{~s}}$ to $284.8 \mathrm{eV}$. The sample appeared as a spin-orbit doublet at $\sim 335.1 \mathrm{eV}\left(\mathrm{Pd} 3 \mathrm{~d}_{5 / 2}\right)$, which was in agreement with the reported value in literature [24, 25]. Consequently,

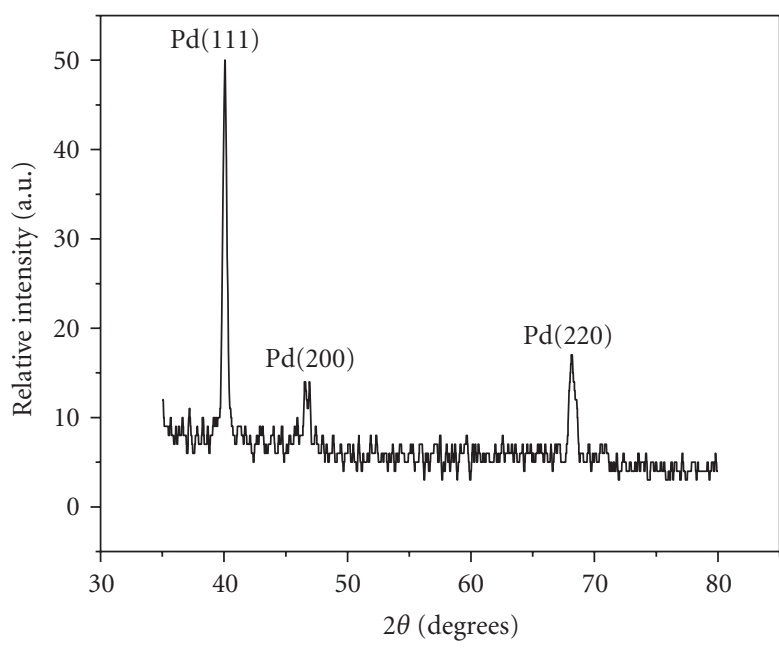

Figure 1: XRD pattern of Pd NWAs.

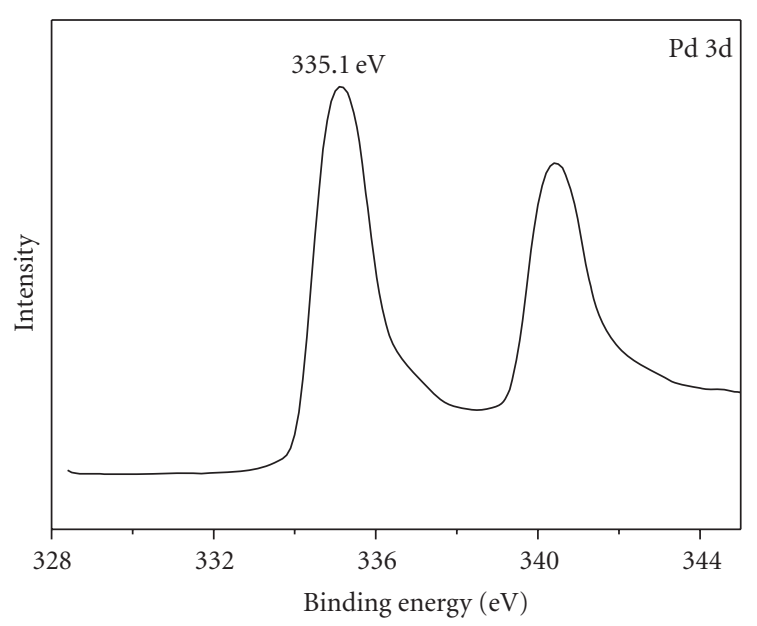

Figure 2: XPS spectra of Pd NWAs.

based on the results of XRD and XPS measurements, the assynthesized products could be determined as Pd.

Figure 3(a) shows a typical SEM image of the prepared AAO template. The image shows an almost-perfect closepacked array of columnar hexagonal cells, each containing a central pore normal to the surface. The porous alumina structure has almost arranged the pore array with the average diameter about $50 \mathrm{~nm}$, the interpaces about $50 \mathrm{~nm}$. Figure 3(b) and Figure 3(c) show the typical images of the Pd NAWs, where the AAO template has completely been dissolved away. It can be clearly observed from Figure 3(b) that the Pd nanowires are highly ordered with uniform diameters of $50 \mathrm{~nm}$, which basically equals to that of the pores of the AAO template. The hexagonal shape of the $\mathrm{Pd}$ nanowires is due to the AAO porous structure during anodization. Figure 3(c) displays the brush shape of $\mathrm{Pd}$ NWAs with length of $850 \mathrm{~nm}$, which is identical to the thickness of the AAO template. The nanowires are uniform, well isolated, parallel to one another, and standing vertically to the electrode substrate surface. Meanwhile, Figure 3(d) 


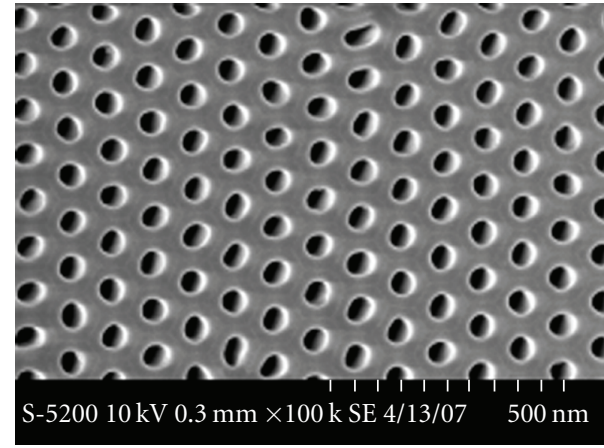

(a)

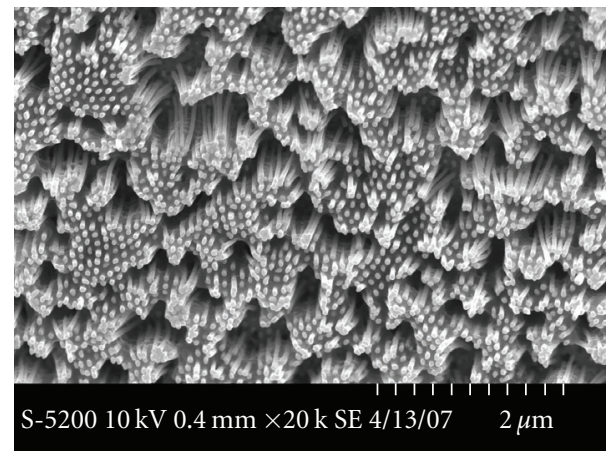

(c)

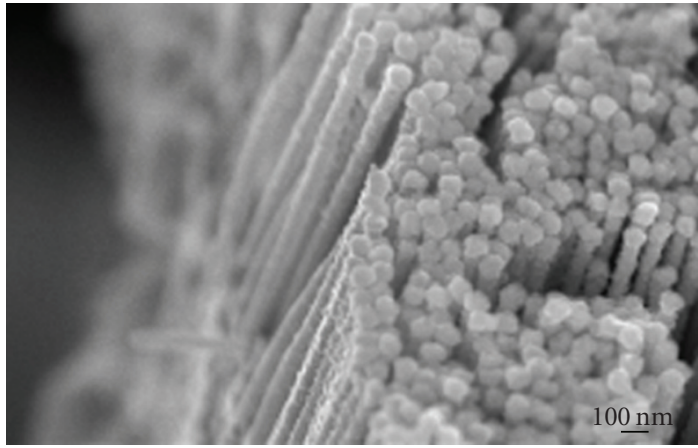

(b)

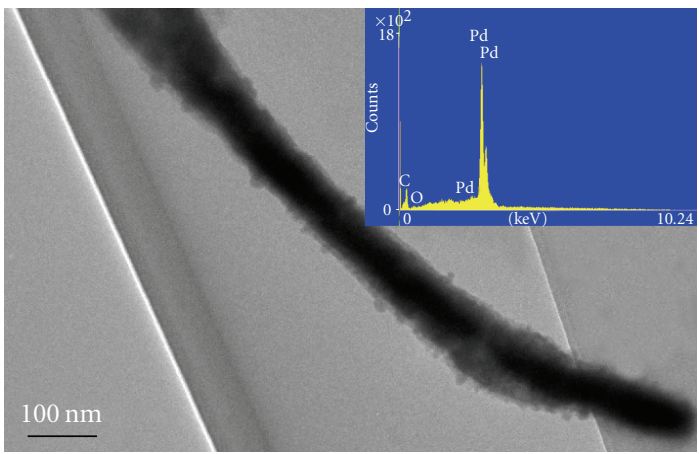

(d)

FIgure 3: Typical SEM images of (a) AAO template, (b) surface of Pd NWA with the diameters of $50 \mathrm{~nm}$, (c) cross section of Pd NWA, and (d) TEM image and EDX (inset) of Pd NWA.

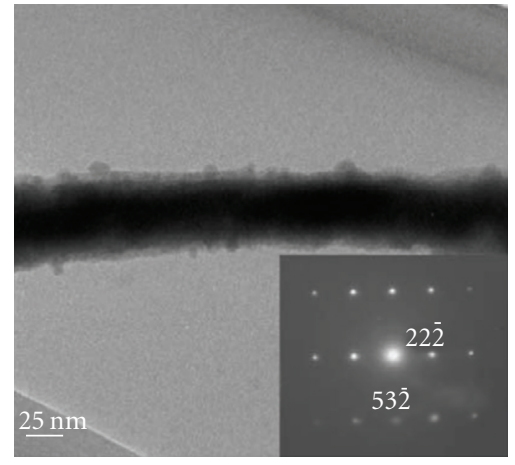

(a)

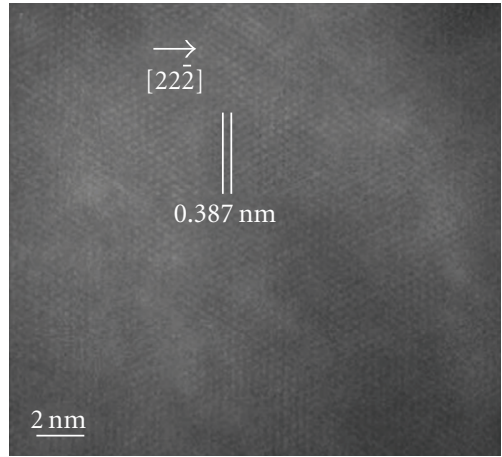

(b)

FIGURE 4: (a) HRTEM image of an individual wire and aSAED pattern (inset) of the wire. (b) HRTEM image of high-quality wire projected along the $[22 \overline{2}]$ axis.

shows the TEM image of Pd nanowire. The inset image in Figure 3(d) is EDX analysis of Pd nanowire arrays. The major peaks are corresponding to palladium, showing that the AAO template was completely removed after treatment in $\mathrm{KOH}$ solution and $\mathrm{Pd}$ nanowire arrays have been successfully fabricated.

To demonstrate the single-crystalline status of $\mathrm{Pd}$ nanowires, HRTEM and selected area electron diffraction (SAED) pattern were taken along the nanowires. SAED was recorded with the electron beam perpendicular to the surface of an individual nanowire, as shown in inset Figure 4(a).
Through careful analysis of the diffraction pattern, the spots could be readily indexed, as marked in the Figure 4(a). The growth of the long axis is along the [22 $\overline{2}]$ direction identified by diffraction of $\mathrm{Pd}$. This conclusion is supported by our subsequent HRTEM investigation. The identified fringe spacing of $0.387 \mathrm{~nm}$ corresponds well with the separation between neighboring [22रे] lattices, as displayed in Figure 4(b). We employed SAED and HRTEM to characterize different nanowires as well as different parts of the same nanowire. All results confirm that the wires grow along the [22र̄] direction. 


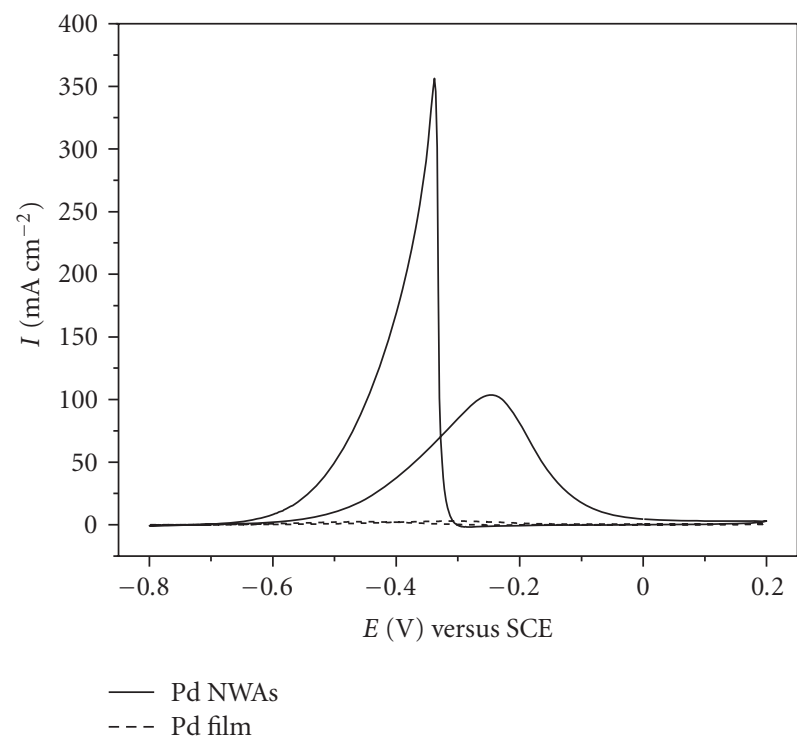

(a)

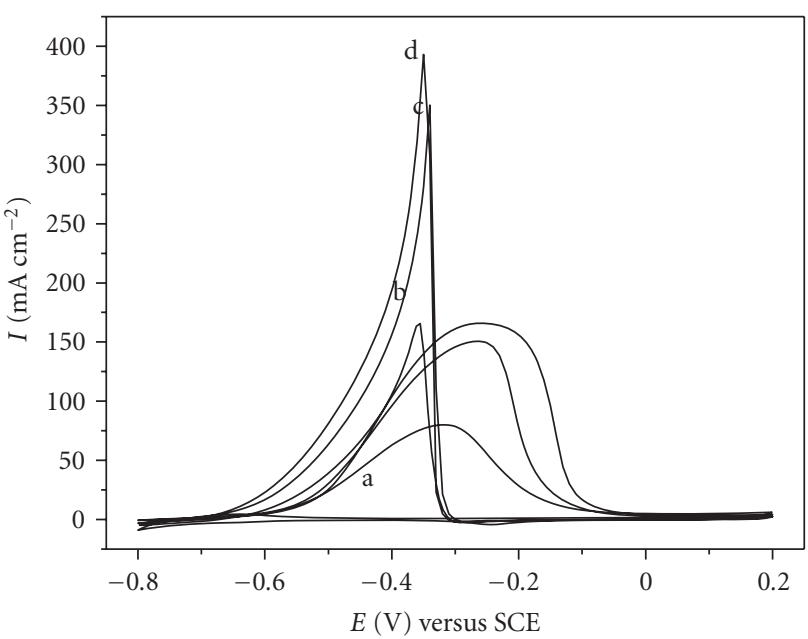

(b)

Figure 5: (a) CVs measured on Pd NWAs electrode with the diameters of about $50 \mathrm{~nm}$ and Pd film electrode in $1.0 \mathrm{M} \mathrm{KOH}+1.0 \mathrm{M}$ propanol solution at a scan rate of $50 \mathrm{mV} \mathrm{s}^{-1}$. (b) CVs of propanol with different concentrations in $1 \mathrm{M} \mathrm{KOH}$ solution on Pd NWA electrode. a: $0 \mathrm{M}$ propanol; b: $0.2 \mathrm{M}$ propanol; c: $0.5 \mathrm{M}$ propanol; d: $1.0 \mathrm{M}$ propanol.

The high electrocatalytic activity of the Pd NWA electrode is demonstrated by its superior performance for the electrooxidation reaction of propanol, as shown in Figure 5(a). The onset potential for propanol oxidation on the Pd NWA electrode is $-0.67 \mathrm{~V}$, which is $190 \mathrm{mV}$ more negative than $-0.48 \mathrm{~V}$ observed on the Pd film electrode. The reduction in the onset anodic potential shows the significant enhancement in the kinetics of the propanol oxidation reaction. Meanwhile, the magnitude of the anodic peak current on Pd NWA electrode is also directly proportional to the amount of propanol oxidized on Pd electrode. The peak current density is 10 and $102 \mathrm{~mA} \mathrm{~cm}^{-2}$ for the reaction on the Pd film and Pd NWA electrodes, respectively. The negatively shifted onset potential and high anodic current for propanol electrooxidation reaction on Pd NWA electrode display that Pd NWA electrodes have much higher electrocatalytic activity than conventional Pd film electrodes in alkaline media. Figure 5(b) shows the cyclic voltammograms of propanol with different concentrations in $1 \mathrm{~mol} / \mathrm{L} \mathrm{KOH}$ solution on the Pd NWA electrode. It can be seen that the oxidation peak current density increases with increasing propanol concentration in the solution. The high current density observed at high propanol concentration may be ascribed to the more mass transport of the reactant. The oxidation peak potential of propanol shifts slightly, showing that catalytic reactions are more favorable at high propanol concentration.

\section{Conclusions}

In summary, highly ordered Pd NWAs have been successfully fabricated on a large scale by the AAO templateelectrodeposition method. The as-prepared Pd nanowires with the diameters of about $50 \mathrm{~nm}$ and the length of $850 \mathrm{~nm}$ have high active surface areas. The electrocatalytic activity of the Pd NWAs for propanol electrooxidation is obviously higher than that of conventional Pd film electrodes. The Pd NWAs presented in this paper show great potential as excellent electrocatalysts for propanol electrooxidation in alkaline media in direct alcohol fuel cells.

\section{Acknowledgments}

This work was financially supported by the Natural Science Foundation of Guangdong Province of China (06108856), the Science and Technology Project of Guangdong Province (2006B12401011), and Application of Nanosensor Technology in the Medical Detection Field (2007108101017).

\section{References}

[1] H.-F. Oetjen, V. M. Schmidt, U. Stimming, and F. Trila, "Performance data of a proton exchange membrane fuel cell using $\mathrm{H}_{2} / \mathrm{CO}$ as fuel gas," Journal of the Electrochemical Society, vol. 143, no. 12, pp. 3838-3842, 1996.

[2] A. Hamnett, "Mechanism and electrocatalysis in the direct methanol fuel cell," Catalysis Today, vol. 38, no. 4, pp. 445457, 1997.

[3] E. Reddington, A. Sapienza, B. Gurau, et al., "Combinatorial electrochemistry: a highly parallel, optical screening method for discovery of better electrocatalysts," Science, vol. 280, no. 5370, pp. 1735-1737, 1998.

[4] Y.-M. Kim, K.-W. Park, J.-H. Choi, I.-S. Park, and Y.-E. Sung, "A Pd-impregnated nanocomposite nafion membrane for use in high-concentration methanol fuel in DMFC," Electrochemistry Communications, vol. 5, no. 7, pp. 571-574, 2003. 
[5] Z. Qi and A. Kaufman, "Open circuit voltage and methanol crossover in DMFCs," Journal of Power Sources, vol. 110, no. 1, pp. 177-185, 2002.

[6] D. Cao and S. H. Bergens, "A direct 2-propanol polymer electrolyte fuel cell," Journal of Power Sources, vol. 124, no. 1, pp. 12-17, 2003.

[7] A. Gunji, C. Wen, J. Otomo, et al., "Carbon deposition behaviour on Ni-ScSZ anodes for internal reforming solid oxide fuel cells," Journal of Power Sources, vol. 131, no. 1-2, pp. 285-288, 2004.

[8] C. Xu and K. S. Pei, "Novel Pt/CeO $/$ /C catalysts for electrooxidation of alcohols in alkaline media," Chemical Communications, vol. 10, no. 19, pp. 2238-2239, 2004.

[9] C. Roychowdhury, F. Matsumoto, V. B. Zeldovich, et al., "Synthesis, characterization, and electrocatalytic activity of PtBi and $\mathrm{PtPb}$ nanoparticles prepared by borohydride reduction in methanol," Chemistry of Materials, vol. 18, no. 14, pp. 3365$3372,2006$.

[10] J. T. Moore, J. D. Corn, D. Chu, et al., "Synthesis and characterization of a $\mathrm{Pt}_{3} \mathrm{Ru}_{1} / \mathrm{Vulcan}$ carbon powder nanocomposite and reactivity as a methanol electrooxidation catalyst," Chemistry of Materials, vol. 15, no. 17, pp. 3320-3325, 2003.

[11] D. C. Geng and G. X. Lu, "Dependence of onset potential for methanol electrocatalytic oxidation on steric location of active center in multicomponent electrocatalysts," Journal of Physical Chemistry C, vol. 111, no. 32, pp. 11897-11902, 2007.

[12] Y.-G. Guo, J.-S. Hu, H.-M. Zhang, H.-P. Liang, L.-J. Wan, and C.-L. Bai, "Tin/platinum bimetallic nanotube array and its electrocatalytic activity for methanol oxidation," Advanced Materials, vol. 17, no. 6, pp. 746-750, 2005.

[13] F. Liu, J. Y. Lee, and W. Zhou, "Multisegment PtRu nanorods: electrocatalysts with adjustable bimetallic pair sites," Advanced Functional Materials, vol. 15, no. 9, pp. 1459-1464, 2005.

[14] F. Liu, J. Y. Lee, and W. J. Zhou, "Segmented Pt/Ru, Pt/Ni, and $\mathrm{Pt} / \mathrm{RuNi}$ nanorods as model bifunctional catalysts for methanol oxidation," Small, vol. 2, no. 1, pp. 121-128, 2006.

[15] G.-Y. Zhao, C.-L. Xu, D.-J. Guo, H. Li, and H.-L. Li, “Template preparation of $\mathrm{Pt}-\mathrm{Ru}$ and $\mathrm{Pt}$ nanowire array electrodes on a Ti/Si substrate for methanol electro-oxidation," Journal of Power Sources, vol. 162, no. 1, pp. 492-496, 2006.

[16] G.-Y. Zhao, C.-L. Xu, D.-J. Guo, H. Li, and H.-L. Li, “Template preparation of $\mathrm{Pt}$ nanowire array electrode on $\mathrm{Ti} / \mathrm{Si}$ substrate for methanol electro-oxidation," Applied Surface Science, vol. 253, no. 6, pp. 3242-3246, 2007.

[17] J. Ye, J. P. Liu, C. Xu, S. P. Jiang, and Y. X. Tong, "Electrooxidation of 2-propanol on Pt, Pd and Au in alkaline medium," Electrochemistry Communications, vol. 9, no. 12, pp. 2760 2763, 2007.

[18] A. L. Prieto, M. M. González, J. Keyani, R. Gronsky, T. Sands, and A. M. Stacy, "The electrodeposition of high-density, ordered arrays of $\mathrm{Bi}_{1-x} \mathrm{Sb}_{x}$ nanowires," Journal of the American Chemical Society, vol. 125, no. 9, pp. 2388-2389, 2003.

[19] R.-L. Zong, J. Zhou, Q. Li, et al., "Synthesis and optical properties of silver nanowire arrays embedded in anodic alumina membrane," Journal of Physical Chemistry B, vol. 108, no. 43, pp. 16713-16716, 2004.

[20] J. Qin, J. Nogués, M. Mikhaylova, A. Roig, J. S. Muñoz, and M. Muhammed, "Differences in the magnetic properties of Co, Fe, and Ni 250-300 nm wide nanowires electrodeposited in amorphous anodized alumina templates," Chemistry of Materials, vol. 17, no. 7, pp. 1829-1834, 2005.

[21] M. S. Sander, A. L. Prieto, R. Gronsky, T. Sands, and A. M. Stacy, "Fabrication of high-density, high aspect ratio, largearea bismuth telluride nanowire arrays by electrodeposition into porous anodic alumina templates," Advanced Materials, vol. 14, no. 9, pp. 665-667, 2002.

[22] H. H. Wang, C. Y. Liu, S. B. Wu, et al., "Highly ramanenhancing substrates based on silver nanoparticle arrays with tunable sub-10 nm gaps," Advanced Materials, vol. 18, no. 4, pp. 491-495, 2006.

[23] H. Wang, C. Xu, F. Cheng, and S. Jiang, "Pd nanowire arrays as electrocatalysts for ethanol electrooxidation," Electrochemistry Communications, vol. 9, no. 5, pp. 1212-1216, 2007.

[24] I. Yuranov, L. Kiwi-Minsker, P. Buffat, and A. Renken, "Selective synthesis of Pd nanoparticles in complementary micropores of SBA-15," Chemistry of Materials, vol. 16, no. 5, pp. 760-761, 2004.

[25] W. J. Zhou and J. Y. Lee, "Particle size effects in Pd-catalyzed electrooxidation of formic acid," Journal of Physical Chemistry C, vol. 112, no. 10, pp. 3789-3793, 2008. 


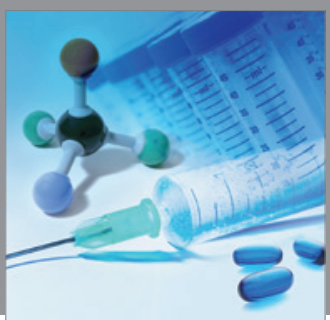

International Journal of

Medicinal Chemistry

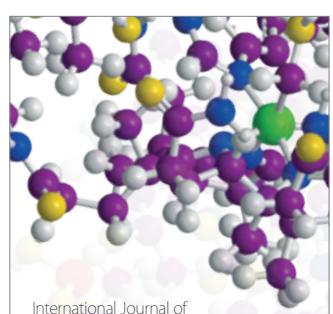

Carbohydrate Chemistry

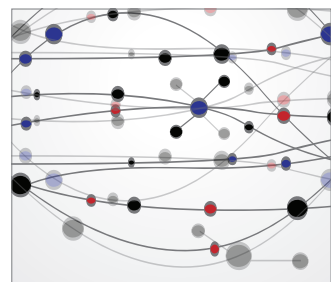

The Scientific World Journal
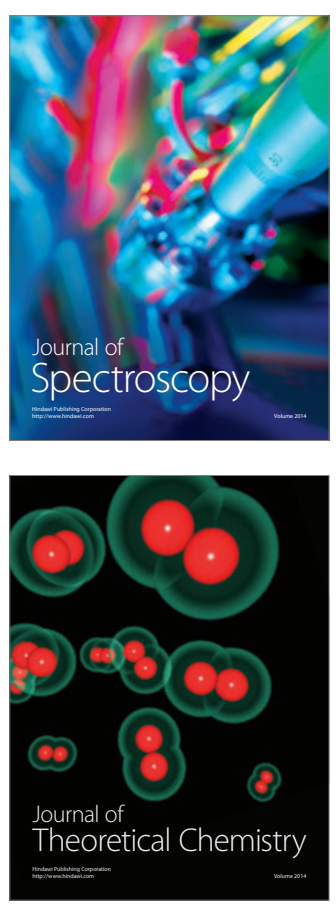
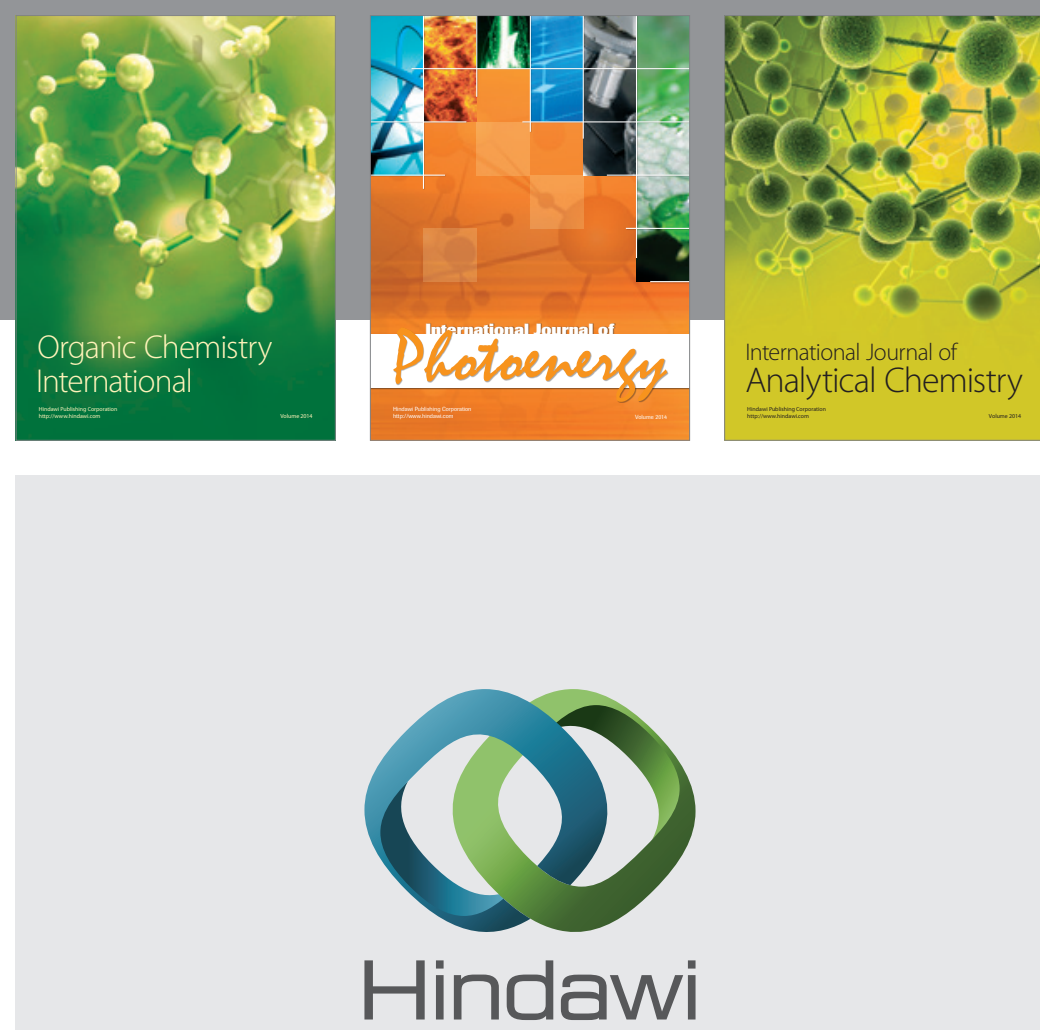

Submit your manuscripts at

http://www.hindawi.com
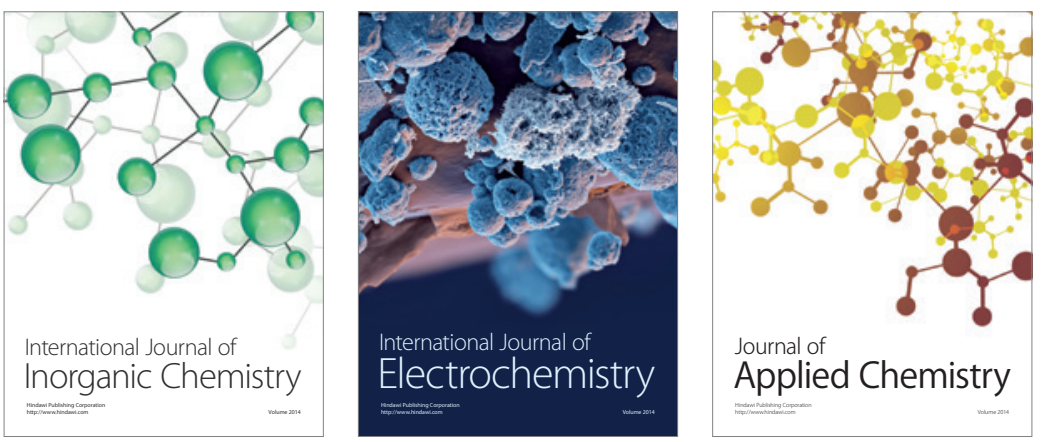

Journal of

Applied Chemistry
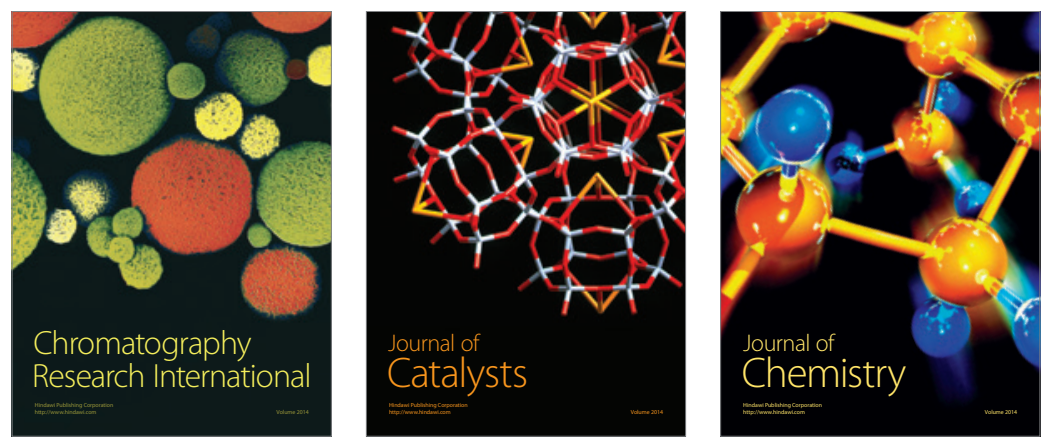
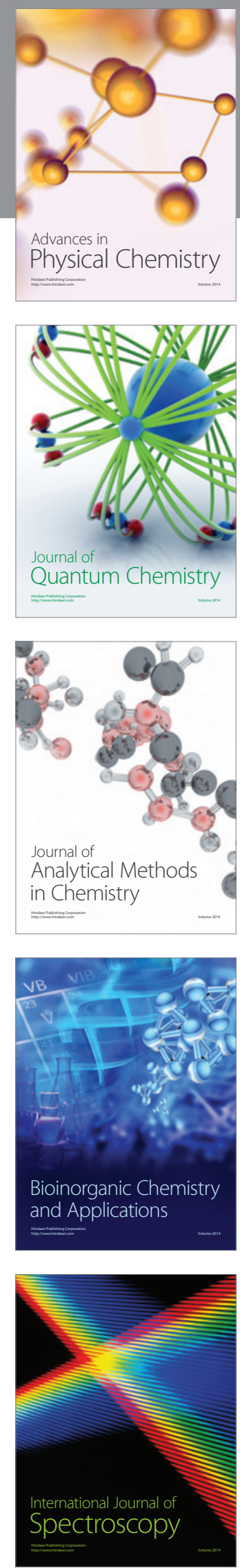